\title{
A MOBILE APPLICATION TO PROMOTE ATTENDANCE AND PARTICIPATION IN THE CLASSROOM
}

\author{
Angélica de Antonio, Cristian Moral, Loïc Martínez, Elena Villalba, Xavier Ferré, \\ Pilar Herrero, Ricardo Imbert, Alberto Sánchez
}

Escuela Técnica Superior de Ingenieros Informáticos, Universidad Politécnica de Madrid (SPAIN)

\begin{abstract}
A mobile application is presented that encourages students to attend classes and promotes their active participation, as a means to reduce absenteeism and to provide assistance for the continuous evaluation of the learning process. In this paper we describe the design of the application and provide some preliminary results of its evaluation.
\end{abstract}

Keywords: Educational Innovation, Class Attendance and Participation, Mobile Application

\section{INTRODUCTION}

Absenteeism and passivity are two big problems that academics at the highereducation level need to recognize and address. In our experience at the B.Sc. Computer Engineering Degree at the Universidad Politécnica de Madrid, less than half of the enrolled students attend classes regularly, with the number of attending students decreasing progressively along the semesters. Students, moreover, tend to be very passive in the classroom, and many proffesors complain that students tend to be more focused on their smartphones than on the contents of the class.

A group of professors of the Human Computer Interaction course, concerned by this situation, decided to research whether an educational tool could help us to promote attendance and participation in our classes.

The working hypothesis of this educational tool is that increasing active class attendance improves the level of understanding of the subject, establishes a greater commitment of the student, and therefore, improves the learning outcomes and decreases the probability of drop-out. However, attendance control is seen by both professors and students as an obtrusive and time-consuming process. Moreover, just attending classes may be useless if the students adopt a passive attitude, refuse to participate in the classroom activities, or are distracted talking to other students or using their mobile phones. It is important to make students feel that they attend classes because they get some value out of this action, and not just because they are forced to do it.

Instead of banning mobile phones in the classroom and considering them as distractors, we intend to draw upon the fact that most, if not all, computer engineering students own smartphones, and we will promote their use in a positive way. We consider essential to make the students use technology, in this case smartphones, to facilitate staying more attentive and interested in classes, instead of letting them use their devices for tasks non-related with the class, like chatting with friends, navigating through the Internet or even playing. 
In the next sections we will present some related work, describe the functionality of the application, and present some preliminary results of the evaluation that is being conducted. Finally, we will discuss these results and describe the work that still remains to be done and our plans for the future.

\section{RELATED WORK}

In the market, there are several applications aiming at tracking the students' attendance and promoting their participation during the classes. In most cases, these applications are designed to facilitate the professor tasks related to teaching, like tracking the students' attendance, creating assignments, or grading the students' homework. Table 1 presents a summary of the functionalities offered by some of the applications that are available nowadays in the market.

Table 1. Features of some applications existing in the market.

\begin{tabular}{|l|c|c|c|c|c|c|}
\cline { 2 - 6 } \multicolumn{1}{l|}{} & $\begin{array}{c}\text { Smart Seat } \\
\text { [1] }\end{array}$ & $\begin{array}{c}\text { Socrative } \\
\text { Teacher [2] }\end{array}$ & $\begin{array}{c}\text { Class } \\
\text { Act! Lite } \\
\text { [3] }\end{array}$ & $\begin{array}{c}\text { iTeacher } \\
\text { Book [4] }\end{array}$ & $\begin{array}{c}\text { Teacher } \\
\text { AldePro [5] }\end{array}$ & $\begin{array}{c}\text { AppTendance } \\
\text { [6] }\end{array}$ \\
\hline $\begin{array}{l}\text { Seating chart } \\
\text { (creation, } \\
\text { visualization, } \\
\text { arrangement) }\end{array}$ & $\mathrm{X}$ & & & & $\mathrm{X}$ & \\
\hline $\begin{array}{l}\text { Attendance } \\
\text { tracking }\end{array}$ & $\begin{array}{c}\mathrm{X} \\
\text { (manually } \\
\text { by the prof.) }\end{array}$ & & & $\begin{array}{c}\mathrm{X} \\
\text { (auto) }\end{array}$ & $\begin{array}{c}\mathrm{X} \\
\text { (manually } \\
\text { by the prof.) }\end{array}$ & $\begin{array}{c}\text { (both manually } \\
\text { and auto) }\end{array}$ \\
\hline $\begin{array}{l}\text { Attendance } \\
\text { history of the } \\
\text { students }\end{array}$ & $\mathrm{X}$ & & $\mathrm{X}$ & & & $\mathrm{X}$ \\
\hline $\begin{array}{l}\text { Random } \\
\text { selection }\end{array}$ & $\mathrm{X}$ & & $\mathrm{X}$ & & & \\
\hline $\begin{array}{l}\text { Make questions } \\
\text { and/or quizzes } \\
\text { (teacher) }\end{array}$ & & $\mathrm{X}$ & & & & $\mathrm{X}$ \\
\hline $\begin{array}{l}\text { Makes } \\
\text { questions } \\
\text { (students) }\end{array}$ & & & & $\mathrm{X}$ & & \\
\hline $\begin{array}{l}\text { Notes about } \\
\text { lesson for the } \\
\text { teacher }\end{array}$ & & & & & & \\
\hline $\begin{array}{l}\text { Schedule of the } \\
\text { teacher's } \\
\text { classes }\end{array}$ & & & & & & \\
\hline $\begin{array}{l}\text { Create and } \\
\text { grade } \\
\text { assignments }\end{array}$ & & & & & & \\
\hline
\end{tabular}

Most of these applications have been designed to be used only by the teacher, and then can be considered as a tool to facilitate his/her teaching tasks. This is probably due to the fact that they are targeted to primary and secondary education, where attendance is mandatory and students may not have a smartphone, or if they have it, they are not allowed to use it during the classes.

Conversely, our objective is promoting attendance and participation at the university, where participation is not always mandatory, and attracting attention and generating interest in students is one of the great challenges for professors. Additionally, in the university context, some aspects like controlling where students seat, or manually and 
individually annotating the attendance of the students becomes infeasible and unhelpful due to the huge number of students that can attend to a class in the University. It is then required to adapt the functionality of the application to the real needs of this specific context of use.

\section{DESCRIPTION OF THE MOBILE APPLICATION}

In order to reach our goal, we have developed a mobile application supporting four basic processes.

\subsection{Group management}

Teachers of a given subject can create as many class groups as it is necessary, both at the beginning of the semester or dynamically. This allows for any kind of reorganization that the course demands. A class group is assigned a code by the application when it is created, and this code should be used by the students to register as members of the group.

Fig. 1 and 2 show how the code is assigned by the application and the way in which the students register in a group.

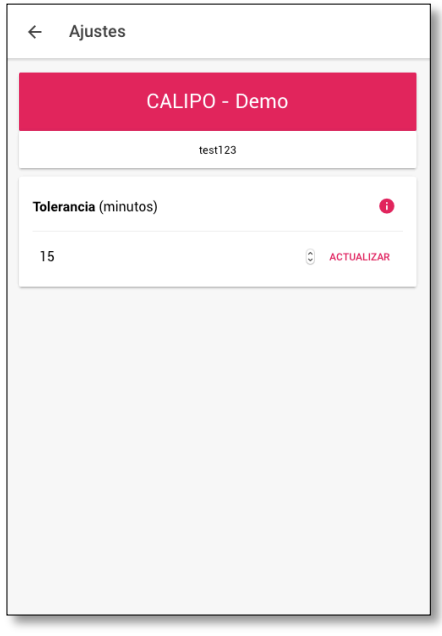

Figure 1. Assignment of group code
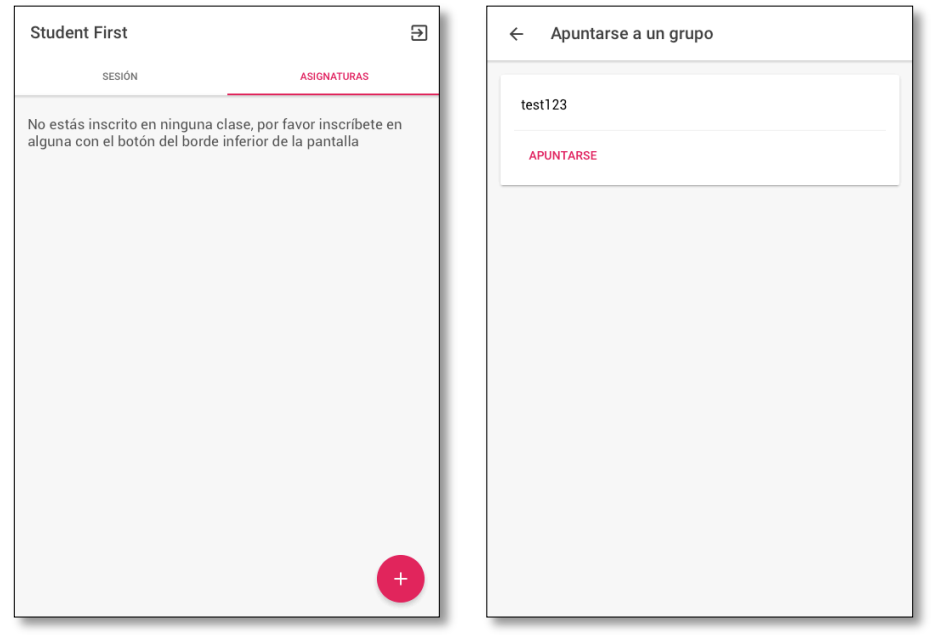

Figure 2. Registration of students in a group

\subsection{Attendance registration}

The application provides a simple and reliable way to let students indicate that they are attending a particular class. Whenever a teacher starts a new class or session in a class group, a 5-digit code will be generated for that session. Fig. 3 shows the initiation of a session by a teacher.

The teacher will write the code in the blackboard, and students, as they arrive to the classroom, will register their attendance by inputting this session code (see Fig. 4). The teacher can define a tolerance interval, that is, the maximum delay that will be admitted for the student's attendance to be considered as on-time. If the student registers beyond this time interval, the application will mark it as "late arrival". 


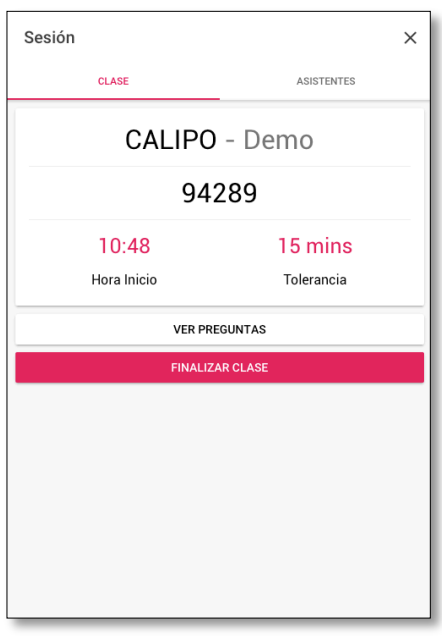

Figure 3. Initiation of a class session.
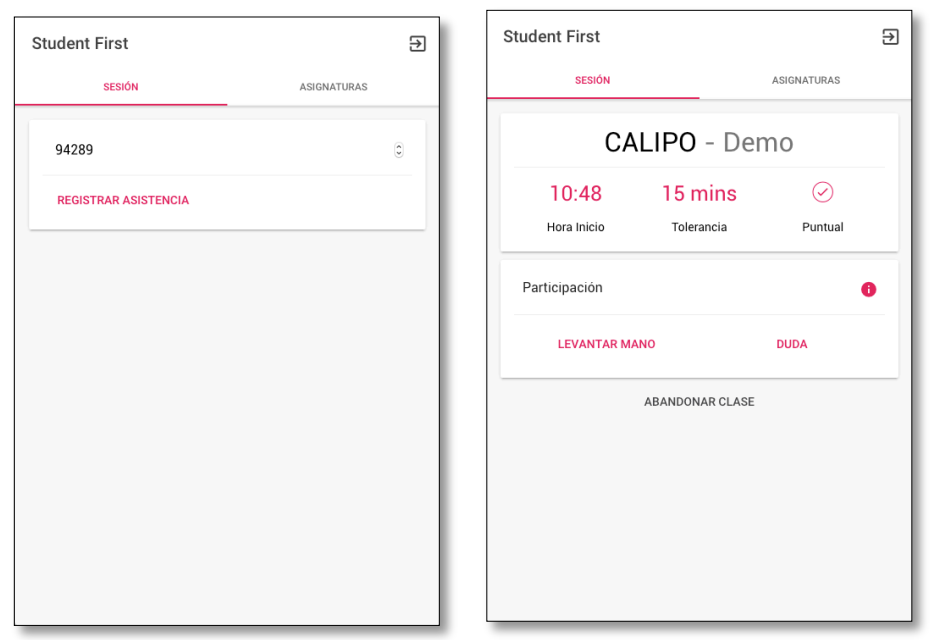

Figure 4. Registration of students in a group

This is not only an unobtrusive attendance control mechanism, but also a facilitator for the communication and interaction of the teacher with the students in the classroom, given that the professor obtains an instant record of the students who are attending the class (see Fig. 5).

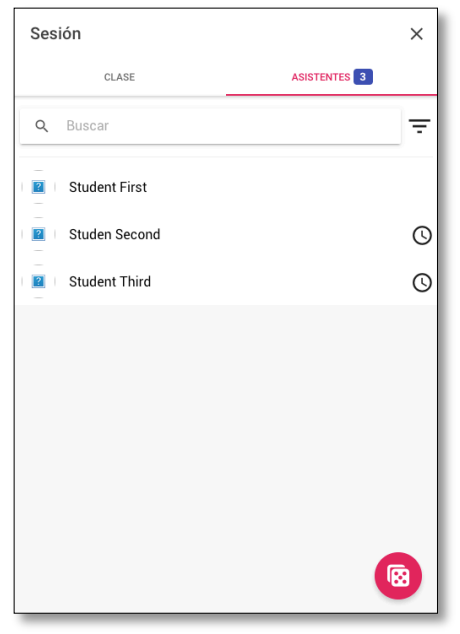

Figure 5. List of attending students showing late arrivals.

\subsection{Promotion of student participation in the classroom}

Students can use the application either to request the floor or to send questions and doubts relative to the professor's explanations as they arise, in case they are not willing to speak aloud.

Fig. 6 shows the way in which students virtually "raise their hands" to request the floor, and Fig. 7 reflects how this fact is shown in the teacher's view by a hand icon next to the student's name in the list of attending students. 

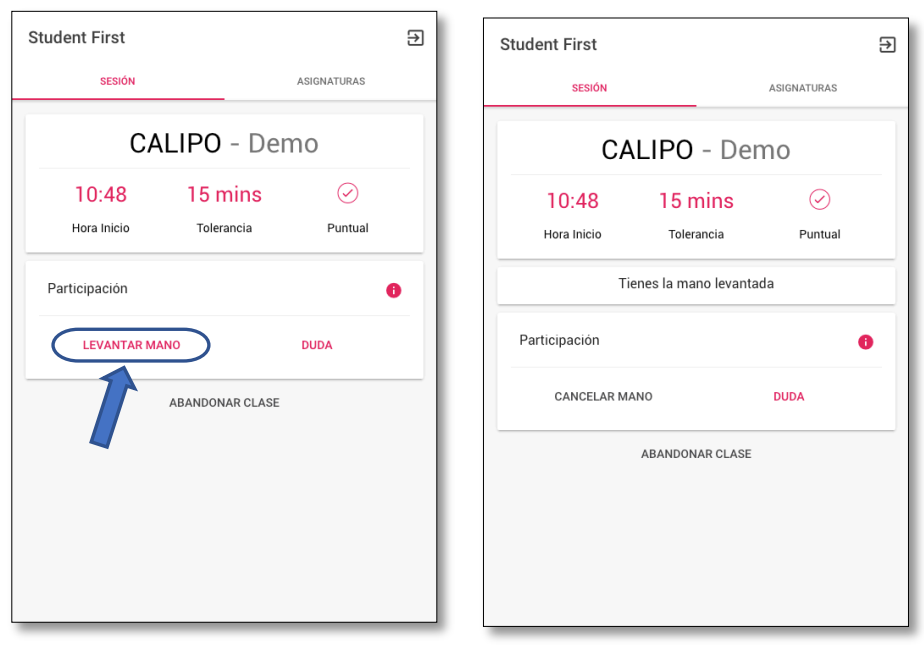

Figure 6. Students requesting the floor.

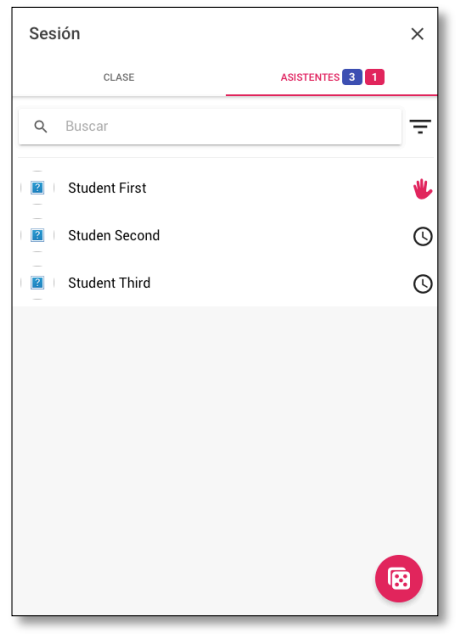

Figure 7. List of students requesting the floor.

In case the student has a doubt but he/she does not like speaking aloud, the application offers the possibility of writing and sending a brief question or observation to the teacher. Fig. 8 shows how the student can input the doubt or comment, and the way in which the teacher receives it and can deal with it is reflected in Fig. 9. Basically there are three options: answering directly to the student via the application (if it is a personal comment); posting a question-and-answer at the course's forum so that all students can learn from this; and just disregarding the student's comment because it is not worth being answered or because the answer will be provided orally in the next class. 

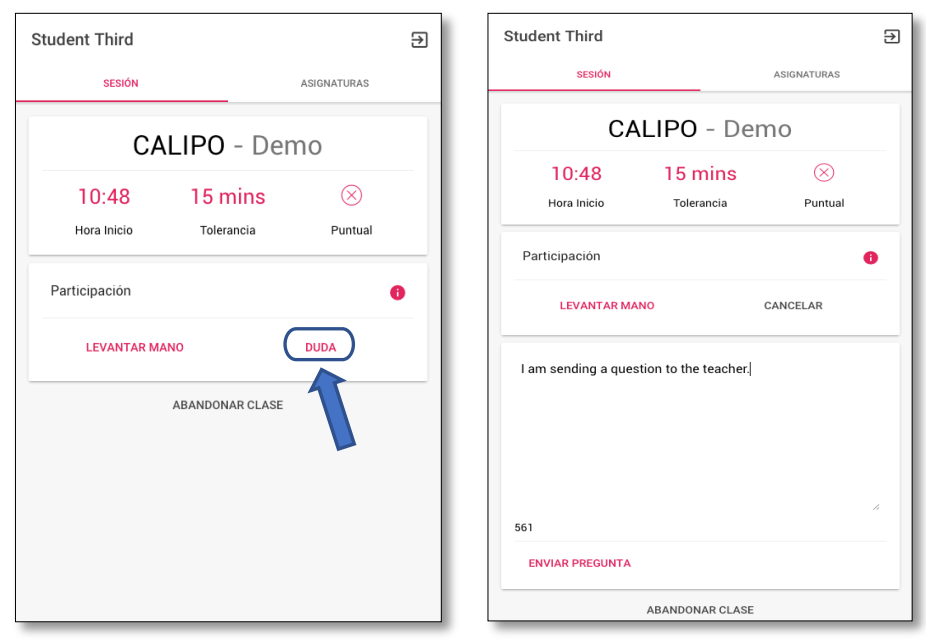

Figure 8. Students sending comments and professors dealing with them.
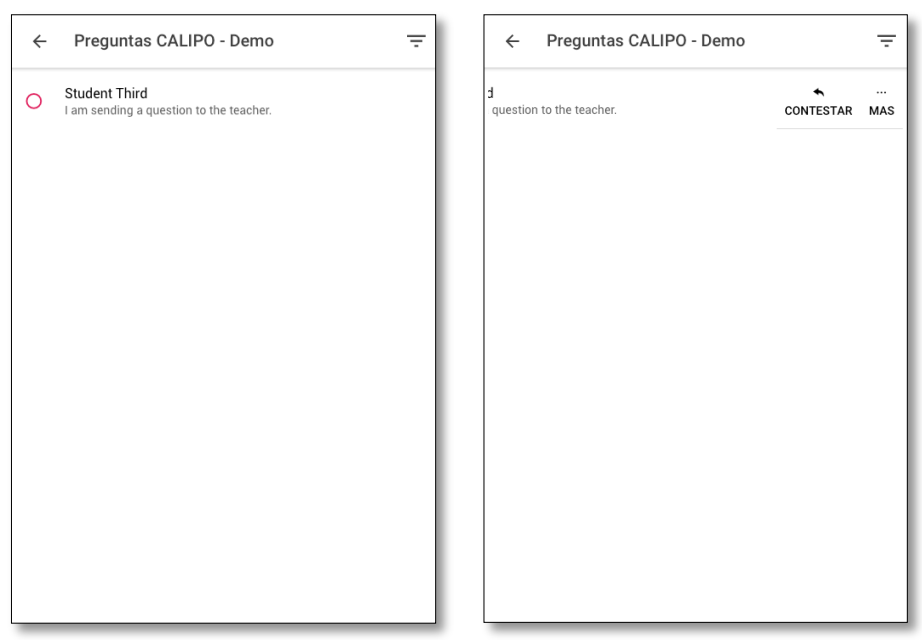

Figure 9. List of questions received by the professor

The professor also has the possibility of explicitly requesting participation from any specific student. The application supports the professor in the selection of the student that will be invited to participate. Fig. 10 shows how the professor can base the selection on the previous history of participation of attending students, and thus invite to participate to those students that were less active. Also, the application can randomly select one student from the list of attending students.

\subsection{Rewarding attendance and participation}

In our experience, students tend to expect and also react positively to some kind of reward for the effort of attending the classes and also for their active participation, particularly those who are not able to appreciate the positive long-term impact on their own learning.

With this application, whenever a student participates, the professor can easily value if the contribution is positive. Attendance and participation logs can then be used for grading.

Fig. 11 shows how the professor can very easily value a student's intervention as positive, negative, or neutral. 


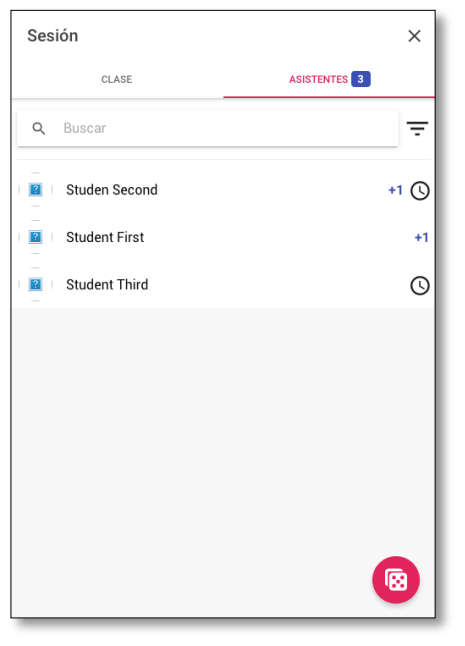

Figure 10. Selection of students for participation initiated by the professor.

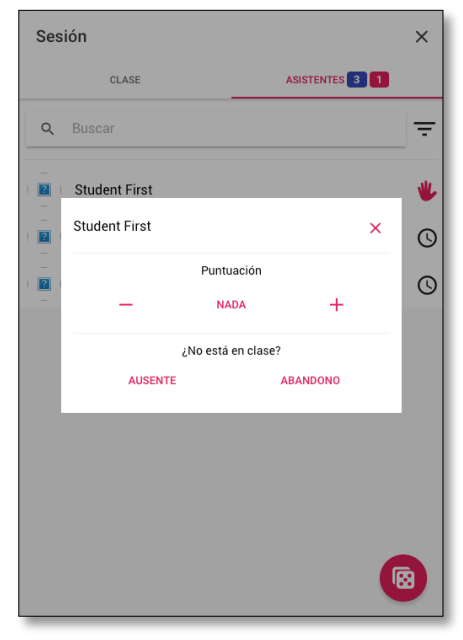

Figure 11. Valuation of the student's participation

\section{EVALUATION}

The application is being evaluated in several ways. First, usability tests are being conducted with both students and professors. Second, a pilot project is being carried out during the fall semester of the 2017-2018 academic year, in the Human-Computer Interaction course of the Computer Engineering degree. Third, the potential acceptability of the tool by academics will be assessed, seeking to identify the main barriers and facilitators for its adoption.

At the time of writing this paper, we already have results concerning the usability of the application, and some preliminary data collected in the pilot project. Acceptability of the tool by academics will be assessed at the end of the current semester with professors not participating in the pilot project.

\subsection{Usability Evaluation}

We have performed a usability evaluation of the current prototype using the System Usability Scale (SUS). There are two groups of users: students (22 undergraduates, 4 master students) and 4 professors.

\subsubsection{Evaluation with Students}

The 22 undergraduate students have answered a SUS questionnaire after using the system during 5 classes. The 4 master students have answered the same SUS questionnaire after performing basic tasks using the system while simulating a class. The results of the SUS score are summarized in table 2 and show a high degree of satisfaction of the users with the system. It is especially relevant the higher result of the undergraduate students who have used the system in a real environment.

Table 2. Summary of SUS score, students.

\begin{tabular}{|c|c|c|c|}
\hline \multicolumn{2}{|c|}{ Undergraduate students (N=22) } & \multicolumn{2}{c|}{ Master degree students (N=4) } \\
\hline Score (average) & Std. dev. & Score (average) & Std. dev. \\
\hline 75,68 & 12,18 & 68,75 & 11,27 \\
\hline
\end{tabular}


As stronger points, the students consider that the system is easy to use and that they felt confident while using the system. The weaker point is that students are not willing to use the system frequently.

\subsubsection{Evaluation with Professors}

Four professors have answered the SUS questionnaire after using the system in their classes. Their scores are summarized in table 3. The professors are the group of users with higher SUS scores. An analysis of the detailed answers provided by them highlights the ease of use and learnability, as well as a clear interest in using the system in the future. The weaker point is a low to medium felt level of confidence, which could be based on the fact of having to use the system as they are teaching.

Table 3. Summary of SUS score, professors.

\begin{tabular}{|c|c|}
\hline Score (average) & Std. dev. \\
\hline 88,13 & 5,15 \\
\hline
\end{tabular}

Those initial usability results show promise for the system usability and acceptability, although we will have to wait to the end of the semester to properly validate the system.

\subsection{Pilot Project}

Both students and professors of the compulsory course "Human-Computer Interaction" (taught in the third year of the Bachelor Degree in Computer Engineering of the Universidad Politécnica de Madrid), have been using the application during the classes, since the beginning of the Fall semester.

In total, the application has been used by 27 students and 5 professors during the first five classes of the course that started in September 2017. Fig. 11 shows that the rate of attendance has reached high levels, between $89 \%$ and $100 \%$.

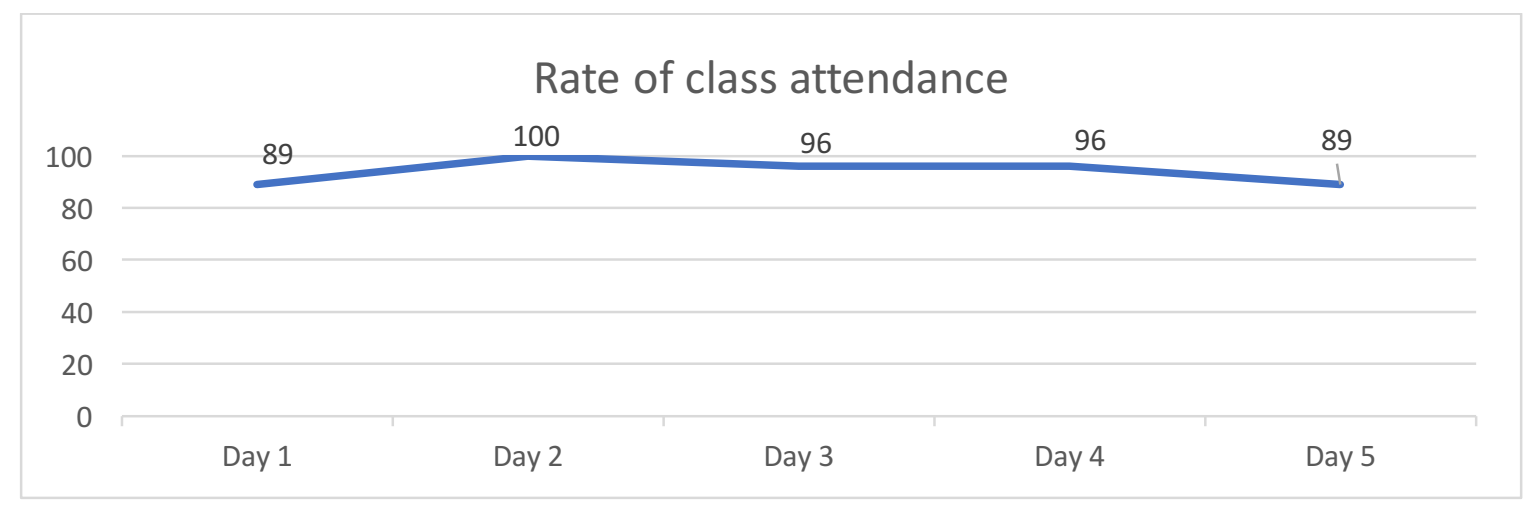

Figure 12. Rate of students attending the classes

In the case of participation, Fig. 12 shows that several students participated many times during the classes using the application, with a peak of $63 \%$ of students participating in the first class, and a more stable rate of participation around $25 \%$ in the subsequent classes. 


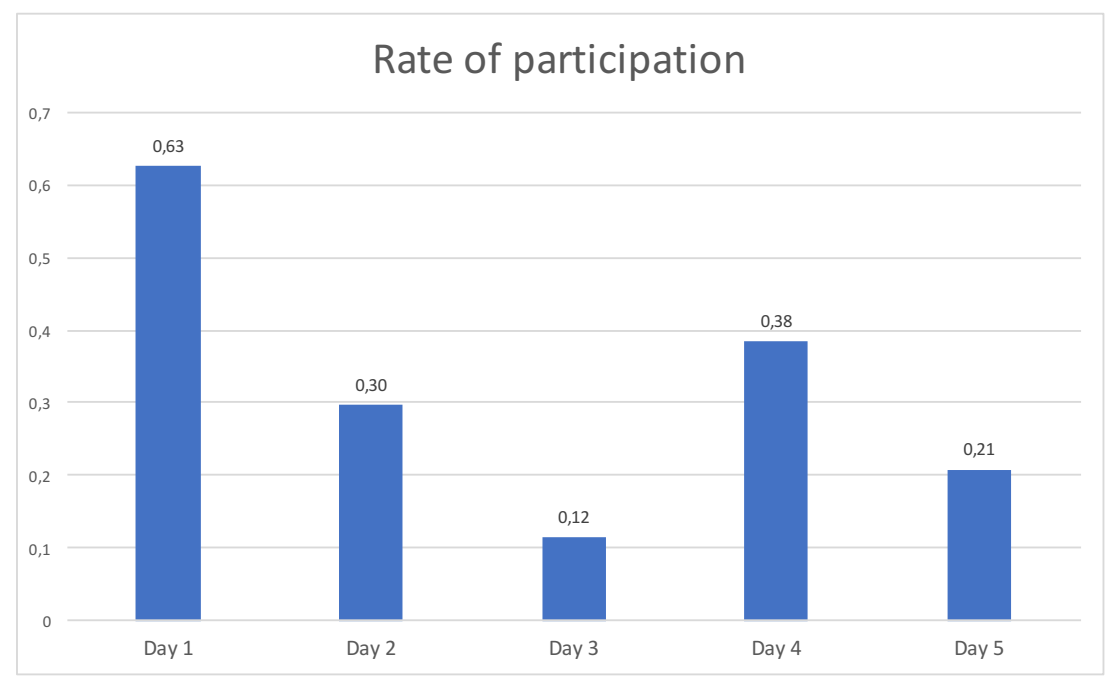

Figure 13. Rate of students who have participated during the classes

These are still preliminary results, but overall they suggest that the use of the application is having a positive impact. An attendance rate close to $100 \%$ is a real success if we consider the typical attendance rate observed in the third course of the degree, which is below $50 \%$ in most of the subjects. This is even more exciting if we consider that attendance is not mandatory in this course, and it is not directly rewarded in the grades.

Regarding participation, the results are less satisfactory, but still promising. The Spanish educational system and culture tend to produce quite passive students that avoid participating in the classes, which usually take the form of a lecture where the professor speaks and the students listen and write. This application can encourage students to be more active by helping professors to keep track of these participations and facilitating the application of appropriate rewards to the student's involvement.

\section{CONCLUSIONS}

This paper has presented the initial efforts in developing and using a mobile application that has been designed to improve two of the biggest perceived problems by University professors: absenteeism and passivity. The application is being used in a undergraduate course in the Universidad Politécnica de Madrid in Spain.

So far, initial results show good promise. Both students and professors have provided good scores for usability and highlight the ease of use and learnability of the system. In addition, student attendance during the first classes has shown high levels. Student participation is rather low, but it is higher than was has been observed in the same course in previous years.

Once the semester is finished, we will perform a more complete evaluation. If the results confirm the good initial evaluation, we intend to extend the use of the application to more courses in our University. 


\section{ACKNOWLEDGEMENTS}

This work is being supported by the Universidad Politécnica de Madrid under the Educational Innovation Programme, project IE1617.1000. We also wish to thank Sergio Barrero and Enrique Nieto, who collaborated in the implementation of the application, as well as Iván Barrera and Ana Laura Bautista, who helped in the development of earlier prototypes.

\section{REFERENCES}

[1] Cornsoft. (2016, 01). Smart Seat. Retrieved 09 2017, from https://itunes.apple.com/app/smartseat/id420586734? $\mathrm{mt}=8$ \&ign-mpt=uo\%3D4

[2] Socrative, Inc. $(2017,02)$. Socrative Teacher. Retrieved 09 2017, from https://itunes.apple.com/us/app/teacher-clicker-socrative/id477620120?mt=8\&ign-mpt=uo\%3D4

[3] Acorn Studios LTD. (2013, 02). Class Act! Lite. Retrieved 09 2017, from https://itunes.apple.com/us/app/class-act!-lite/id601325167?mt=8\&ign-mpt=uo\%3D4

[4] iStudiez Team. $(2015,06)$. iTeacherBook. Retrieved 09 2017, from https://itunes.apple.com/app/iteacherbook/id459153342? mt=8

[5] Glen Botha. (2017, 09). Teacher Aide Pro. Retrieved 09 2017, from https://itunes.apple.com/us/app/teacher-aide-pro/id1059855768?mt=8

[6] Grange García, C. E. (2014, 07). Desarrollo de una aplicación android para el control automático de la asistencia a clase. Retrieved from Biblos-e Archivo de la Universidad Autónoma de Madrid: https://repositorio.uam.es/handle/10486/662279 